\title{
BMJ Open Antihypertensive drug effects according to the pretreatment self-measured home blood pressure: the HOMED-BP study
}

\author{
Hikari Sano, ${ }_{1}^{1}$ Azusa Hara, ${ }^{2}$ Kei Asayama (D) , ${ }^{3,4,5}$ Seiko Miyazaki, ${ }^{1}$ \\ Masahiro Kikuya, ${ }^{4}$ Yutaka Imai, ${ }^{5}$ Takayoshi Ohkubo ${ }^{4,5}$
}

To cite: Sano H, Hara A, Asayama K, et al. Antihypertensive drug effects according to the pretreatment self-measured home blood pressure: the HOMED-BP study. BMJ Open 2020;10:e040524. doi:10.1136/ bmjopen-2020-040524

- Prepublication history and additional material for this paper is available online. To view these files, please visit the journal online (http://dx.doi.org/10. 1136/bmjopen-2020-040524)

Received 18 May 2020

Revised 17 November 2020

Accepted 17 November 2020

Check for updates

(c) Author(s) (or their employer(s)) 2020. Re-use permitted under CC BY-NC. No commercial re-use. See rights and permissions. Published by BMJ.

${ }^{1}$ Social Pharmacy and Regulatory Science, Showa Pharmaceutical University,

Machida, Japan

${ }^{2}$ Division of Drug Development and Regulatory Science, Faculty of Pharmacy, Keio University,

Minato-ku, Japan

${ }^{3}$ Research Unit Hypertension and Cardiovascular Epidemiology, KU Leuven Cardiovascular Sciences, Leuven, Belgium

${ }^{4}$ Hygiene and Public Health,

Teikyo University School of

Medicine, Itabashi-ku, Japan

${ }^{5}$ Tohoku Institute for

Management of Blood Pressure,

Sendai, Japan

Correspondence to

Dr Kei Asayama;

kei@asayama.org

\section{ABSTRACT}

Objectives To clarify whether or not the antihypertensive drug effect is proportional to the baseline pretreatment self-measured home blood pressure (HBP) in accordance with the law of initial value (Wilder's law).

Design A post-hoc analysis of a multicentre clinical trial. Setting Outpatients across Japan with mild-to-moderate essential hypertension.

Participants Among 3518 randomised participants, 2423 who self-measured HBP during the pretreatment drug-free period (10-28 days after starting fixed-dose antihypertensive monotherapy) with a mean 7.0 years follow-up were eligible.

Main outcome measures We analysed individual HBP readings during pretreatment and monotherapy.

Results The day-to-day HBP during both the pretreatment period and monotherapy period remains almost the same throughout each period; the results were consistent, regardless of the pretreatment HBP. Following monotherapy, the reduction in the HBP increased by $2.2 \mathrm{~mm} \mathrm{Hg}(95 \% \mathrm{Cl}: 1.8$ to $2.5 \mathrm{~mm} \mathrm{Hg})$ per $10 \mathrm{~mm} \mathrm{Hg}$ pretreatment HBP increase, up to $11.0 \mathrm{~mm} \mathrm{Hg}(95 \% \mathrm{Cl}$ : 9.9 to $12.0 \mathrm{~mm} \mathrm{Hg}$ ) among patients with an $\mathrm{HBP} \geq 165$ $\mathrm{mm} \mathrm{Hg}$ during pretreatment. Among the 1005 patients receiving low-dose monotherapy (defined daily dose: 0.5 units), the reduction peaked at $8.9-9.1 \mathrm{~mm} \mathrm{Hg}$ in those with pretreatment HBP $155-164 \mathrm{~mm} \mathrm{Hg}$ and $\geq 165 \mathrm{~mm} \mathrm{Hg}$ $(p=0.88)$.

Conclusions According to Wilder's law, the HBP reduction due to fixed-dose monotherapy was proportional to the pretreatment HBP without any regression to the mean phenomenon. With low-dose antihypertensive drugs, however, the HBP reduction peaked in patients with a high pretreatment HBP, indicating the need for such patients to receive a sufficient amount of antihypertensive drug medication at the initial treatment

Trial registration UMIN Clinical Trial Registry (http://www. umin.ac.jp/ctr), Unique identifier: C000000137.

\section{INTRODUCTION}

Hypertension is a major risk factor for cardiovascular disease. ${ }^{12}$ A meta-analysis showed that a $10 / 5 \mathrm{~mm} \mathrm{Hg}$ reduction in conventional office systolic/diastolic blood pressure reduces the stroke risk by approximately $40 \%$ and the coronary artery disease risk by approximately 20\%. ${ }^{3}$ However, office blood

\section{Strengths and limitations of this study}

This is a post-hoc analysis of a multicentre clinical trial in which patients were recruited from 457 general practices throughout Japan.

- Enroled 2423 patients with mild-to-moderate essential hypertension measured their daily selfmeasurement of blood pressure at home during the pretreatment period, after antihypertensive monotherapy, and for a mean 7.0 years follow-up.

- Home blood pressure was self-measured using a validated upper-arm cuff-oscillometric OMRON HEM 747IC-N device, in which all measured data, including the measurement time, were automatically recorded.

- We were unable to assess the placebo effect because all patients received antihypertensive medication.

- Limitations of the studies included large number of excluded participants (1095 of the randomised 3518 patients) by which we should practice caution when applying the findings regarding antihypertensive drug effect to real-world clinical practice.

pressure has major limitations including being affected by the white-coat phenomenon, that is, a warning response wherein the office blood pressure unexpectedly rises when in an examination room in front of medical staff. ${ }^{4}$ In contrast, self-measured home blood pressure (HBP) assessed using automated devices in a non-medical setting can obtain a plurality of readings over a long period under relatively uniform conditions, resulting in highly reproducible values without observer bias when patients apply a standardised protocol. ${ }^{245}$ Home monitoring is unaffected by the white-coat phenomenon and is suitable for the evaluation of drug efficacy. ${ }^{2}{ }^{56}$ Given its greater prognostic ability for cardiovascular complications than office blood pressure, ${ }^{1}{ }^{7-9}$ HBP-based antihypertensive treatment is highly recommended. ${ }^{29}$

Recent studies ${ }^{10} 11$ have reported that the higher the pretreatment blood pressure, the 
greater the reduction in the blood pressure by antihypertensive drug treatment, according to the law of initial value (Wilder's law). ${ }^{12}$ However, the reduction in the 24 hours ambulatory blood pressure corresponding to the pretreatment office blood pressure was shown to be relatively small. ${ }^{10}$ Such disproportionality can be attributed to changes in the white-coat effect, which depends on pretreatment office blood pressure..$^{10}$ Although ambulatory and HBPs are both categorised as out-of-office blood pressure, the characteristics and usefulness of HBP differ from those of ambulatory recordings, ${ }^{129}$ and no report has described differences in antihypertensive drug effects according to the pretreatment blood pressure.

We therefore investigated the association between the pretreatment home and office blood pressure levels and HBP reduction by antihypertensive monotherapy as well as long-term blood pressure changes in patients participating in a HBP-based clinical trial.

\section{METHODS}

\section{Study design}

This was a post-hoc analysis of the Hypertension Objective Treatment based on Measurement by Electrical Device of Blood Pressure (HOMED-BP) study, ${ }^{13-15}$ which was a multicentre clinical trial with a prospective, randomised, open-label, blinded end point, evaluation ${ }^{16}$ design. The HOMED-BP protocol complies with the Declaration of Helsinki with respect to the ethical principles for medical research involving human subjects ${ }^{17}$ and is registered with the UMIN Clinical Trial Registry, number C000000137 (http://www.umin.ac.jp/ctr). The institutional review board of the Teikyo University School of Medicine approved the study (17-044-2), and all study participants gave their written informed consent.

We included patients with mild-to-moderate essential hypertension based on HBP (135-179/85-119 mm Hg) with a minimum age of 40 years old; they were recruited from 457 general practices throughout Japan. ${ }^{14}{ }^{15}$ The exclusion criteria were severe hypertension (HBP $\geq 180 / \geq 120 \mathrm{~mm} \mathrm{Hg}$ or office blood pressure $\geq 220 / \geq 125$ $\mathrm{mm} \mathrm{Hg}$ ), meeting the systolic criteria for the HBP $(\geq 135 \mathrm{~mm} \mathrm{Hg}$ ) but with a diastolic HBP of $<65 \mathrm{~mm} \mathrm{Hg}$, meeting the diastolic HBP criteria $(\geq 85 \mathrm{~mm} \mathrm{Hg})$ but with a systolic HBP of $<110 \mathrm{~mm} \mathrm{Hg}$, or contraindications to either calcium channel blockers, angiotensin-converting enzyme inhibitors or angiotensin receptor blockers.

\section{Selection of patients}

After the first visit at the initial registration, the 5211 enroled patients were followed up for at least 2 weeks without any antihypertensive drugs. At the second visit, the $3518(67.5 \%)$ eligible patients were randomised in a $2 \times 3$ design to receive monotherapy with the first-line drug (calcium channel blockers, angiotensin-converting enzyme inhibitors or angiotensin receptor blockers) with target HBP-based antihypertensive values (usual control, ranging from 125 to $134 \mathrm{~mm} \mathrm{Hg}$ systolic and 80 to $84 \mathrm{~mm}$
$\mathrm{Hg}$ diastolic; tight control, $<125 \mathrm{~mm} \mathrm{Hg}$ systolic and $<80$ $\mathrm{mm} \mathrm{Hg}$ diastolic). The reasons for excluding the other 1693 patients before randomisation have been described elsewhere $^{14}$ and listed in online supplemental figure 1.

In the present analysis, we excluded 1095 of the randomised 3518 patients because they had obtained $<3$ home readings at baseline (pretreatment period; $\mathrm{n}=102$ ) or during fixed-dose monotherapy with the first-line drug $(\mathrm{n}=592)$, they had isolated diastolic hypertension (HBP $\leq 135 / \geq 85 \mathrm{~mm} \mathrm{Hg} ; \mathrm{n}=143$ ), they did not actually receive an antihypertensive drug or had been treated with $\geq 2$ drug classes simultaneously $(n=37)$, or we were unable to assess the blood pressure or treatment status during follow-up $(\mathrm{n}=221)$. A total of 2423 participants were analysed statistically (online supplemental figure 1). Based on our previous report indicating that the risks of cardiovascular outcomes were similar in the randomised groups (tight vs usual blood pressure control, and a comparison of drug classes to initiate treatment) because of the small blood pressure difference between the groups, ${ }^{14}$ we combined all 2423 participants in the present analysis.

\section{Measurements of blood pressure}

Patients enroled in Hypertension Objective Treatment based on Measurement by Electrical Device of Blood Pressure (HOMED-BP) received spoken and written instructions on blood pressure self-measurement and the utilisation of a validated cuff-oscillometric OMRON HEM 747IC-N (Omron Healthcare Co, Ltd, Kyoto, Japan), ${ }^{18}$ in which all measured data, including the measurement time, are automatically recorded. The standard upper-arm cuff, which covered 22-32 cm of a patient's arm circumference, was attached to the device. The importance of using an appropriately sized cuff was noted in the user's manual of the device, and we provided another cuff on request. Throughout the study period, patients were asked to self-measure their blood pressure at home once every morning within 1 hour of awakening, after urination, before breakfast, before taking antihypertensive medication and after 2 min rest in a sitting position.

Office blood pressure was measured by doctors in the outpatient clinic using a validated cuff-oscillometric OMRON HEM-907 (Omron Healthcare Co, Ltd). ${ }^{19}$ At each visit, the office blood pressure was measured twice consecutively in a sitting position after at least 2 min rest.

\section{The evaluation of the blood pressure}

In this study, the baseline pretreatment HBP was the average of all blood pressure measurements taken for 5 days before the second visit on randomisation, and the blood pressure during the monotherapy was the average of measurements taken for 5 days within the 10-to-28-day period after the initiation of randomised first-line drugs (figure 1) ${ }^{20}$ We used this time window for home readings because (1) the HBP used for determining eligibility and treatment adjustments at every visit in the HOMED-BP study was the average of the home readings available over 5 days immediately preceding the visit; ${ }^{14}(2)$ the clinical 


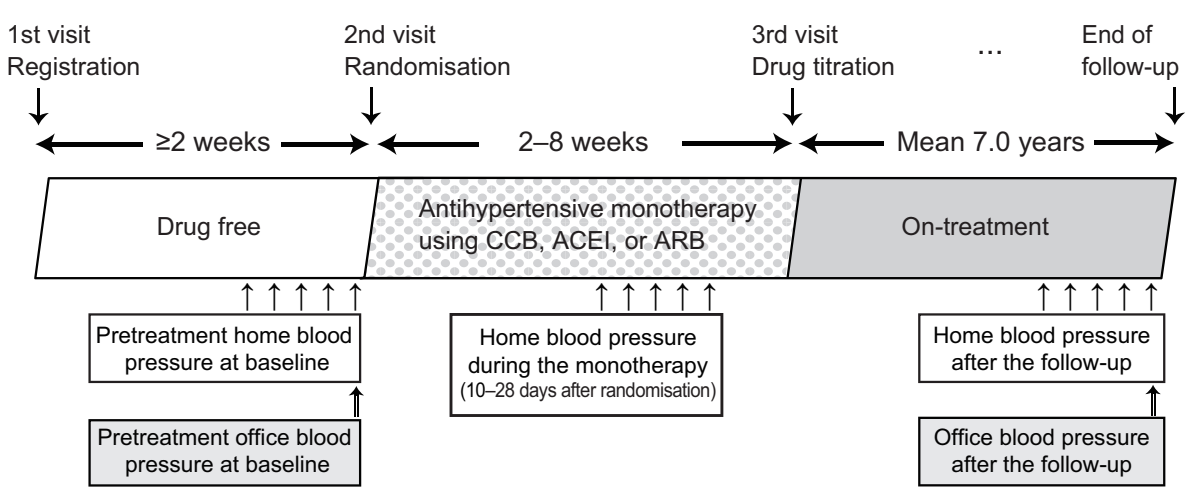

Figure 1 Time course of blood pressure measurement during the study period. HBPs were the average of 5 days before randomisation without any antihypertensive treatment, after 10-28 days of monotherapy, and at the end of the follow-up period. Patients with 3-4 days of HBP data in each interval were also included. ACEI, angiotensin-converting enzyme inhibitor; ARB, angiotensin receptor blocker; CCB, calcium channel blocker; HBP, home blood pressure.

investigators followed the patients at intervals of approximately 2-4 weeks in general practice and approximately 4-8 weeks at hospital outpatient clinics; and (3) the time interval needed to receive sufficient antihypertensive effects is reported to be approximately $7-23$ days. ${ }^{21}$ All of the HBP values evaluated in the present study were therefore captured before the third visit, when drug titration might have been performed. The HBP at the end of follow-up (mean follow-up period: 7.0 years; IQR: 5.1-9.1 years) was defined as the average of the last available 5 days of HBP values. The office blood pressure during pretreatment and follow-up were the averages of the two consecutive measurements at each visit. The reduction in the blood pressure was calculated as the change from the pretreatment blood pressure at baseline.

\section{Definition of comorbidity and quantification of drugs}

The body mass index was calculated as the body weight in kilograms divided by the height in metres squared. Diabetes mellitus was defined as a fasting plasma glucose level of $\geq 7.0 \mathrm{mmol} / \mathrm{L}(\geq 126 \mathrm{mg} / \mathrm{dL})$, haemoglobin A1c of $\geq 6.5 \%$, or treatment with oral antidiabetic drugs or insulin. Hypercholesterolaemia was defined as a total serum cholesterol level of $\geq 5.69 \mathrm{mmol} / \mathrm{L}(\geq 220 \mathrm{mg} /$ $\mathrm{dL}$ ), a history of hypercholesterolaemia or taking lipidlowering drugs. ${ }^{1420}$

We used the WHO's defined daily dose (DDD) to quantify the use of antihypertensive drugs ${ }^{22}$; the DDD is the standard maintenance dose per day for a drug used for its main indication in adults. ${ }^{22}$ The standard usage per day is defined as a DDD of 1 unit.

\section{Statistical analyses}

For database management and statistical analyses, we used the SAS software package, V.9.4 (SAS Institute Inc, Cary, North Carolina, USA). Statistical significance was set at an $\alpha<0.05$ on two-sided tests. We focused on our analyses based on systolic blood pressure, as systolic pressure is the overriding risk factor in middle-aged and older people. ${ }^{23}$

Patients were divided into four groups $(\leq 145,145-154$, 155-164 and $\geq 165 \mathrm{~mm} \mathrm{Hg}$ ) according to the baseline pretreatment systolic HBP, and the blood pressure reduction was compared among the groups. For office blood pressure assessments, patients were stratified into $10 \mathrm{~mm}$ $\mathrm{Hg}$ groups according to the pretreatment systolic office blood pressure, as in the report by Schmieder et al. ${ }^{10}$ The $\chi^{2}$ test and an analysis of variance were used to compare the baseline characteristics between groups appropriately. $\mathrm{HBP}$ values during the five pretreatment days as well as those during the five monotherapy days were compared by a repeated measure mixed linear model, as implemented in the PROC MIXED procedure of the SAS package with the residual maximum likelihood option as the estimation method for the covariance parameters and the Kenward and Roger approximation ${ }^{24}$ for the df calculations. The blood pressure reduction was compared among groups according to the pretreatment blood pressure using an analysis of covariance, and the change in the blood pressure reduction per pretreatment blood pressure increase was calculated using a linear regression model. In both analyses, the sex, age, body mass index, current smoking and drinking habit, hypercholesterolaemia, diabetes mellitus and history of cardiovascular disease were used for adjustments. The DDD during the initial antihypertensive monotherapy and at the end of follow-up were further used as the adjustment factors to compare the pressure reduction from pretreatment to the initial treatment and to the end of follow-up, respectively. For the 40 patients without body mass index data, we interpolated the value based on the sex and age (continuous). The white-coat effect was defined as the office blood pressure minus the HBP as a continuous variable (negative value if the HBP was higher than the office blood pressure), ${ }^{102526}$ and changes in the white-coat effect were determined by subtracting the effect observed at the end of the follow-up period from the effect captured during pretreatment.

\section{Patient and public involvement}

No patients were involved in setting the research question or the outcome measures, nor were they involved in developing the plans for recruitment, design or 
Table 1 Baseline characteristics of patients

\begin{tabular}{|c|c|c|c|c|c|}
\hline \multirow[b]{2}{*}{ Characteristics } & \multicolumn{5}{|c|}{ Systolic HBP at baseline, $\mathrm{mm} \mathrm{Hg}$} \\
\hline & $<145$ & $145-154$ & $155-164$ & $\geq 165$ & $P$ value \\
\hline Number of participants & 763 & 699 & 544 & 417 & \\
\hline Women, $\mathrm{n}$ & $416(54.5)$ & $342(48.9)^{\star}$ & $275(50.6)$ & $202(48.4)$ & 0.11 \\
\hline Age, years & $59.3(10.0)$ & $59.3(9.7)$ & $61.0(9.8) \dagger$ & $61.3(9.5)$ & 0.0003 \\
\hline Body mass index, $\mathrm{kg} / \mathrm{m}^{2}$ & $24.2(3.5)$ & $24.2(3.2)$ & $24.6(3.4)$ & $24.8(3.2)$ & 0.0017 \\
\hline Smoking, $\mathrm{n}$ & $142(18.6)$ & $138(19.7)$ & $112(20.6)$ & $109(26.1)^{\star}$ & 0.019 \\
\hline Drinking, $\mathrm{n}$ & $347(45.5)$ & $344(49.2)$ & $270(49.6)$ & $211(50.6)$ & 0.27 \\
\hline Diabetes mellitus, $\mathrm{n}$ & $122(16.0)$ & $101(14.4)$ & 85 (15.6) & $70(16.8)$ & 0.74 \\
\hline Hypercholesterolaemia, n & 399 (52.3) & $372(53.2)$ & $287(52.8)$ & $203(48.7)$ & 0.49 \\
\hline Previous cardiovascular diseases, $n$ & $25(3.3)$ & $17(2.4)$ & $17(3.1)$ & $7(1.7)$ & 0.37 \\
\hline \multicolumn{6}{|l|}{ HBP } \\
\hline Systolic, $\mathrm{mm} \mathrm{Hg}$ & $139.8(3.0)$ & $149.6(2.9) \ddagger$ & $159.4(2.8) \ddagger$ & $171.3(4.3) \ddagger$ & $<0.0001$ \\
\hline Diastolic, mm Hg & $84.4(8.4)$ & 89.8 (8.9)‡ & 92.6 (10.0)‡ & $95.9(10.9) \ddagger$ & $<0.0001$ \\
\hline \multicolumn{6}{|l|}{ Office blood pressure } \\
\hline Systolic, mm Hg & $147.7(15.5)$ & $153.7(16.5) \ddagger$ & $157.8(16.5) \ddagger$ & $165.4(17.1) \ddagger$ & $<0.0001$ \\
\hline Diastolic, $\mathrm{mm} \mathrm{Hg}$ & $87.1(11.2)$ & $90.4(11.8) \ddagger$ & $91.1(12.3)$ & $94.0(13.1) \S$ & $<0.0001$ \\
\hline
\end{tabular}

Values are expressed as the arithmetic mean (SD) or number (\%). P values were calculated by an analysis of variance or the $\chi^{2}$ test among the four systolic HBP groups at baseline during pretreatment. For missing values of body mass index $(\mathrm{n}=40)$, single imputation with regression on sex and age was conducted.

*Significance of differences from the left adjacent column: $p<0.05$. $\dagger$ Significance of differences from the left adjacent column: $p<0.01$. $\ddagger$ Significance of differences from the left adjacent column: $p<0.0001$. $\S$ Significance of differences from the left adjacent column: $p<0.001$. HBP, home blood pressure.

implementation of the study. No patients were asked to advise on the interpretation or writing up of the results. There are no specific plans to disseminate the results of the research to study participants or the relevant patient community beyond the usual channels of publication.

\section{RESULTS}

\section{Representativeness of the study patients}

Online supplemental table 1 shows the baseline characteristics of the 2423 patients included in the present analysis, along with the other 1095 randomised patients excluded from the analysis and the 694 patients who were randomised but not included because they measured their HBP $<3$ times. Although statistically significant differences were found in the age $(\mathrm{p} \leq 0.030)$, systolic blood pressure $(p \leq 0.0064)$ for the comparison between analysed patients and all excluded patients, and in the drinking habit and history of cardiovascular disease $(p \leq 0.020)$ for the comparison between analysed patients and patients who were excluded due to an insufficient number of HBP measurements, all other characteristics were similar.

\section{Patients' characteristics}

Table 1 shows the baseline characteristics of 2423 patients. The average age of all participants was 60.0 (SD: 9.8) years old, and the proportion of women was $51.0 \%$. The age, body mass index, smoking habit and office blood pressure were significantly and positively associated with the baseline systolic blood pressure category. As shown in table 2, the day-to-day HBP measurements during both the pretreatment period and monotherapy period remains almost the same throughout each period. When patients were subdivided by the systolic HBP at baseline, there were significant differences between the patients with a HBP $<145 \mathrm{~mm} \mathrm{Hg}$ during the pretreatment period ( $\mathrm{p}=0.032)$ and 145-154 $\mathrm{mm} \mathrm{Hg}$ during the monotherapy period ( $p=0.035)$; however, the differences between adjacent days were not significant even among those patients $(\mathrm{p} \geq 0.12)$.

The relationship of the white-coat effect and office or home blood pressure values during the pretreatment period as a cross-sectional approach is shown in online supplemental figure 2. The white-coat effect increased along with the office blood pressure $(7.5 \mathrm{~mm} \mathrm{Hg}, 95 \% \mathrm{CI}$ : 7.3 to $7.8 \mathrm{~mm} \mathrm{Hg}$, per $10 \mathrm{~mm} \mathrm{Hg}$ increment), whereas the HBP was negatively related to the white-coat effect $(-4.5$ $\mathrm{mm} \mathrm{Hg}, 95 \%$ CI: -3.9 to $-5.0 \mathrm{~mm} \mathrm{Hg}$, per $10 \mathrm{~mm} \mathrm{Hg} \mathrm{HBP}$ increment).

Reduction in the HBP by monotherapy according to the pretreatment blood pressure

During the initial fixed-dose monotherapy, the reduction in the systolic HBP was increased by $2.2 \mathrm{~mm} \mathrm{Hg}$ 
Table 2 Home systolic blood pressure values according to the measurement days

\begin{tabular}{|c|c|c|c|c|c|c|c|}
\hline $\begin{array}{l}\text { Baseline blood } \\
\text { pressure } \\
\text { category }\end{array}$ & $\begin{array}{l}\text { Number of } \\
\text { patients }\end{array}$ & \multicolumn{6}{|c|}{ HBP measurement days (times) } \\
\hline \multicolumn{8}{|l|}{$\begin{array}{l}\text { Pretreatment, } \\
\mathrm{mm} \mathrm{Hg}\end{array}$} \\
\hline All & 2423 & $152.5(14.7)$ & $152.5(14.8)$ & $152.2(14.9)$ & $152.4(14.6)$ & $152.6(14.9)$ & 0.48 \\
\hline$<145$ & 763 & $140.3(9.1)$ & $139.6(8.4)$ & $139.1(8.8)$ & $139.7(8.2)$ & $140.4(9.6)$ & 0.032 \\
\hline $155-164$ & 544 & $159.3(10.3)$ & $158.7(10.3)$ & $159.5(9.6)$ & $159.8(9.7)$ & $159.8(10.5)$ & 0.41 \\
\hline$\geq 165$ & 417 & $170.9(11.3)$ & $172.0(10.3)$ & $171.1(10.4)$ & $171.0(11.2)$ & $171.4(11.5)$ & 0.66 \\
\hline \multicolumn{8}{|l|}{$\begin{array}{l}\text { Monotherapy, } \\
\mathrm{mm} \mathrm{Hg}\end{array}$} \\
\hline All & 2423 & 145.5 (17.0) & 145.2 (16.9) & $145.4(16.5)$ & $145.4(16.5)$ & 144.7 (16.6) & 0.58 \\
\hline $155-164$ & 544 & $150.2(15.3)$ & $150.5(15.4)$ & $150.5(14.6)$ & $151.2(14.4)$ & $150.5(14.7)$ & 0.67 \\
\hline$\geq 165$ & 417 & $161.1(16.5)$ & $160.0(17.0)$ & $160.3(15.4)$ & $160.1(16.1)$ & $160.5(15.9)$ & 0.65 \\
\hline
\end{tabular}

Values are expressed as the arithmetic mean (SD). The numbers of patients with missing blood pressure data on the fourth and fifth days were 38 and 84 at pretreatment and 87 and 286 during monotherapy, respectively, while $p$ values were calculated by a repeated measure mixed linear model to take missing values into account and represent the differences among the five systolic HBP values according to the measurement day at baseline during pretreatment.

Differences between the adjacent days were not significant during pretreatment $(p \geq 0.12)$ or monotherapy $(p \geq 0.14)$. HBP, home blood pressure.

(95\% CI: 1.8 to $2.5 \mathrm{~mm} \mathrm{Hg}$ ) per $10 \mathrm{~mm} \mathrm{Hg}$ pretreatment HBP increase. The reductions in each baseline pretreatment blood pressure group are shown in figure 2. The slope of the HBP reduction accompanying the increase in the pretreatment office blood pressure was shallower, increasing by $0.6 \mathrm{~mm} \mathrm{Hg}$ (95\% CI: 0.4 to $0.9 \mathrm{~mm} \mathrm{Hg}$ ) per $10 \mathrm{~mm} \mathrm{Hg}$ pretreatment office blood pressure increase.

\section{Stratification by the DDD}

Figure 3 demonstrates the results according to the DDD of the initial antihypertensive drugs. Among 1005 patients who started monotherapy with antihypertensive drugs of 1 unit DDD, the pretreatment HBP was linearly associated with the blood pressure reduction at the time of monotherapy; the enhancement of the HBP reduction for each increase in the pretreatment HBP category was $2.6 \mathrm{~mm} \mathrm{Hg}$ (95\% CI: 1.9 to $3.2 \mathrm{~mm} \mathrm{Hg}$ ). However, among those receiving 0.5 units DDD $(\mathrm{n}=1005$; осcasionally the same number), significant enhancement in HBP reductions was observed up to the 155-164 mm Hg group (per one group increase, $2.1 \mathrm{~mm} \mathrm{Hg}$; 95\% CI: 1.2 to $2.9 \mathrm{~mm} \mathrm{Hg}$ ), where it peaked; the reductions in the HBP among patients with a pretreatment HBP of $155-164 \mathrm{~mm} \mathrm{Hg}$ and $\geq 165 \mathrm{~mm} \mathrm{Hg}$ were 8.9 and $9.1 \mathrm{~mm}$ $\mathrm{Hg}$, respectively $(\mathrm{p}=0.88)$. The results were confirmed when we divided the whole 2423 patients according to a DDD of $<1$ or $\geq 1$ unit, as shown in online supplemental figure 3 .

\section{Reduction in the follow-up blood pressure according to the pretreatment blood pressure}

According to the previous report based on ambulatory blood pressure monitoring, ${ }^{10}$ we compared the home and office blood pressure reductions at the end of follow-up according to the baseline pretreatment office blood pressure. After 7.0 years follow-up with a mean DDD of 1.8 units (median: 1.5; IQR: 1.0-2.5), the reduction in the office blood pressure was linearly associated with the office blood pressure during pretreatment (reduction in the home pressure from the office blood pressure category $<140$ to $\geq 180 \mathrm{~mm} \mathrm{Hg:7.5}$ to $50.7 \mathrm{~mm} \mathrm{Hg}$; figure 4). Furthermore, similar to the previous report based on ambulatory monitoring, ${ }^{10}$ the reduction in the HBP was linearly associated with the office blood pressure during the pretreatment period; however, the degree of HBP reduction per the pretreatment office blood pressure increase was weak (reduction in home pressure: 18.6 to $30.7 \mathrm{~mm} \mathrm{Hg}$ ). Finally, changes in the white-coat effect during the follow-up period increased significantly as the pretreatment office blood pressure increased (online supplemental figure 4; category increment $\mathrm{p}<0.0001$ ).

\section{DISCUSSION}

The antihypertensive drug effect depends on the pretreatment blood pressure. In line with Wilder's law, ${ }^{12}$ the HBP reduction after the initial drug treatment was proportional to the baseline pretreatment HBP in the present 


\section{Pretreatment systolic blood pressure $(\mathrm{mmHg})$}

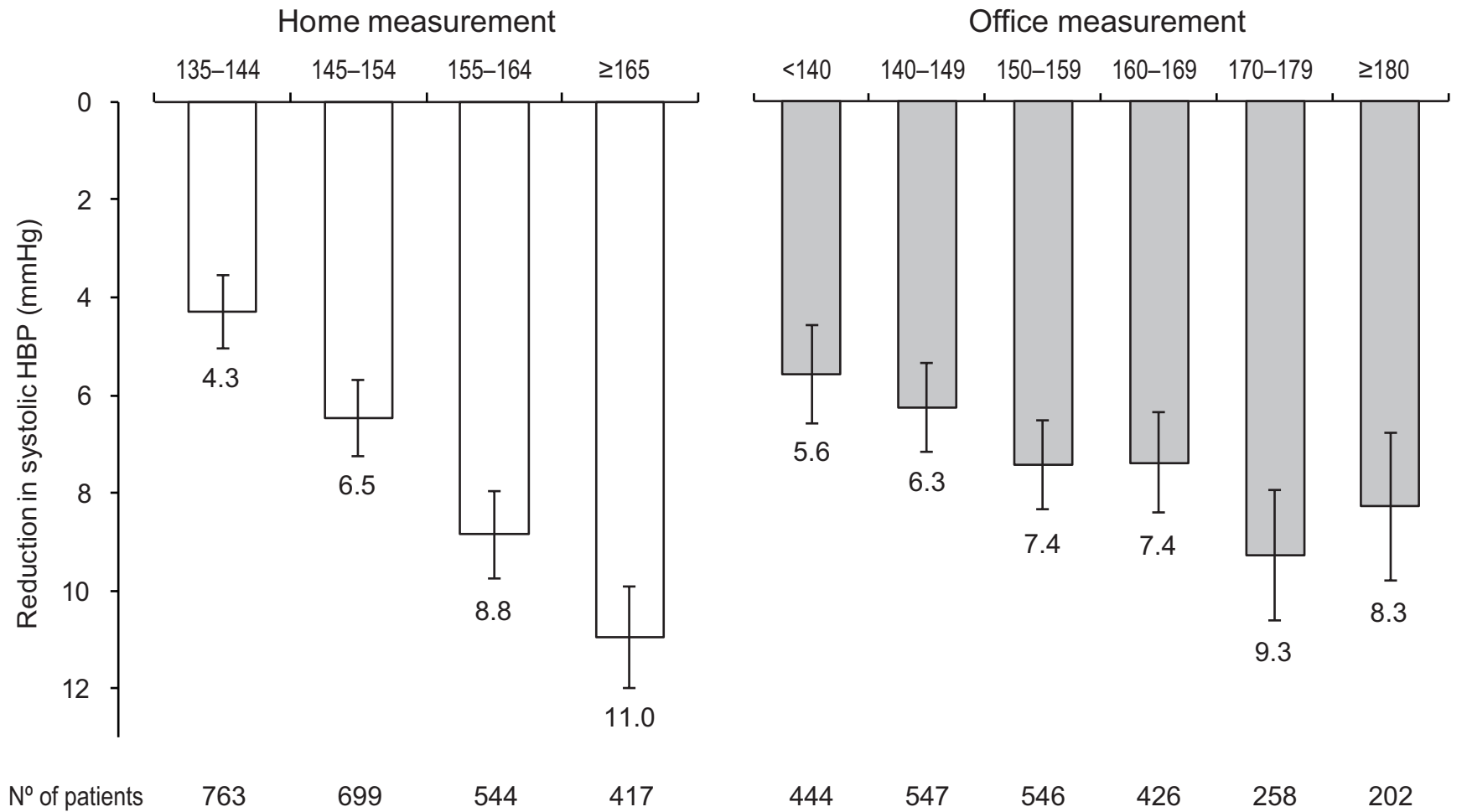

Figure 2 Reduction in the systolic HBP during monotherapy categorised by pretreatment home (left panel) and office (right panel) blood pressure. Error bars indicate the $95 \% \mathrm{Cl}$. Data were adjusted for sex, age, body mass index, diabetes mellitus, current smoking and drinking, hypercholesterolaemia, history of cardiovascular disease and DDD during monotherapy. DDD, defined daily dose; HBP, home blood pressure.

study. The current findings emphasise the need to assess the HBP before treatment when evaluating and initiating antihypertensive drug therapy.

Wilder indicated that the direction of the body function response depends to a large extent on the initial level of that function, regardless of the agent. ${ }^{12}$ Wilder's law predicts that in the most patients with severe hypertension, the decrease in blood pressure will be greater with the same medication than in those with less-severe hypertension. The statistical phenomenon of regression to the mean (regression towards the mean) is another major confounding factor hampering the accurate assessment of the effect of antihypertensive agents. ${ }^{27}$ However, as shown in table 2, there were no regression trends in the HBP values from the first to the final measurement during the pretreatment or monotherapy periods, regardless of the pretreatment HBP. This finding indicates the strength of the self-measurement of HBP, as home measurement is associated with minimal (if any during an initial few days after the measurement begins ${ }^{28}$ regression to the mean). ${ }^{5629}$ Based on ambulatory blood pressure monitoring, regression to the mean was observed consistently among the five studies, ${ }^{30}$ and a portion of the reduction in blood pressure after initiating antihypertensive treatment can be explained by this phenomenon. ${ }^{30}$ However, there have been no reports investigating the biological mechanism contributing to this reduced influence of the regression to the mean phenomenon on self-measured HBP. Nevertheless, HBP measurement is likely to be useful for estimating the efficacy of antihypertensive drugs.

Schmieder et $a l^{10}$ reported that the higher the baseline office blood pressure, the greater the blood pressure reduction after 1 year of treatment enhancement, and this was more obvious in the office blood pressure than in the ambulatory blood pressure. ${ }^{10} \mathrm{~A}$ recent meta-analysis also showed that the overall treatment-induced reduction was greater for office blood pressure than for 24 hours ambulatory blood pressure. ${ }^{11}$ In the present study, the reduction in the office blood pressure at the end of a mean 7.0 years follow-up was also greater than that in the self-measured HBP (figure 4). Schmieder t $a l^{10}$ attributed this discrepancy to the changes in the white-coat effect, that is the higher the baseline office blood pressure, the greater the decrease in the white-coat effect due to antihypertensive treatment. This assumption was also supported by the findings of the present study (online supplemental figure 4); however, the white-coat effect may not be a main driver for the discrepancy because the HBP reduction also followed Wilder's law despite the negative correlation between HBP and white-coat effect during the pretreatment period. Nevertheless, the 


\section{Pretreatment systolic HBP $(\mathrm{mmHg})$}
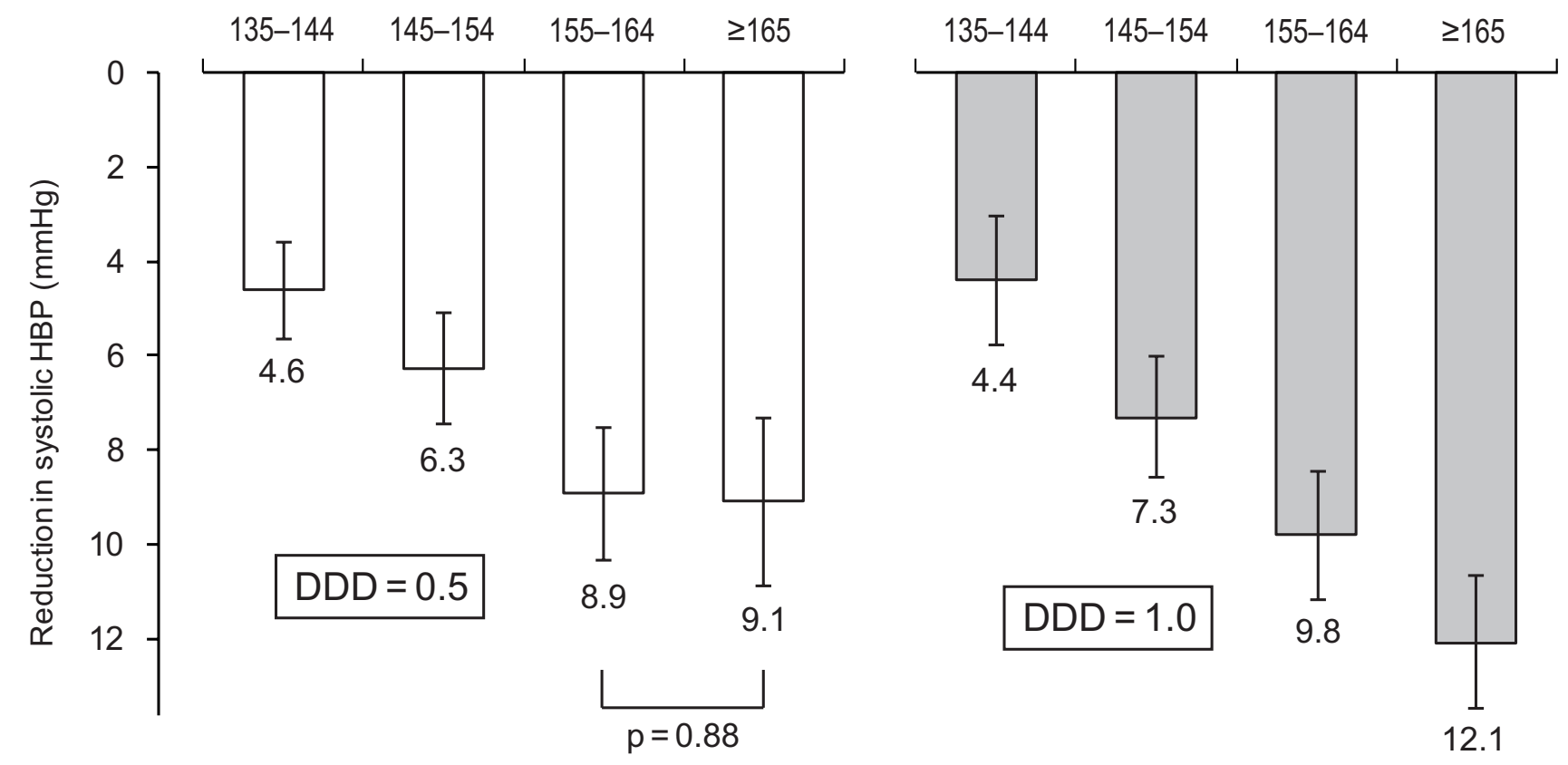

$\mathrm{N}^{0}$ of patients

382

293

203

127

248

276

243

238

Figure 3 Reduction in the systolic HBP during monotherapy categorised by pretreatment HBP, stratified by DDD (0.5 units, left panel; 1 unit, right panel). Error bars indicate 95\% Cls. Data were adjusted for sex, age, body mass index, diabetes mellitus, current smoking and drinking, hypercholesterolaemia and history of cardiovascular disease. DDD, defined daily dose; HBP, home blood pressure.

out-of-office blood pressure is theoretically free from the white-coat phenomenon, ${ }^{4}$ and the reduction in the office blood pressure by antihypertensive treatment partially includes a reduction in the white-coat effect as well. We should therefore follow-up out-of-office-measured blood pressure carefully, since patients with a higher blood pressure tend to show a greater antihypertensive effect when their values are based on office-based measurements, while their out-of-office blood pressure reduction might be insufficient, resulting in a persistent high risk for cardiovascular complications.

Among 1005 patients who were taking low-dose antihypertensive drugs, namely at a DDD of 0.5 units, the reduction in HBP during monotherapy in the group with a pretreatment HBP of $\geq 165 \mathrm{~mm} \mathrm{Hg}$ was almost identical to that in the group with a pretreatment HBP of 155-164 $\mathrm{mm} \mathrm{Hg}$. A high HBP is associated with a high cardiovascular disease risk over the long term, both before and during antihypertensive therapy. ${ }^{14} 15$ Inadequate control of office blood pressure with antihypertensive drug therapy remains a critical issue in Japan ${ }^{31}$ as well as in Europe ${ }^{32}$ and the USA. ${ }^{33}$ Previous studies ${ }^{34} 35$ have shown the importance of rapid blood pressure control, and the current findings suggest that a sufficient dosage of antihypertensive drug from the beginning of treatment is necessary, particularly among those with a high HBP before starting treatment.
Although the need to strengthen antihypertensive drug treatment has been gradually accepted, ${ }^{129}$ various factors associated with medical providers, patients and healthcare systems have contributed to clinical inertia (non-compliance). ${ }^{36} 37$ Clinical inertia is associated with inadequate blood pressure control, resulting in the increased risk of adverse cardiovascular effects. Medical services should help overcome clinical inertia as well as other hindrances in order to improve the blood pressure control of patients. Self-measurement of HBP is expected to ameliorate the status quo because it promotes an improved awareness among patients with high blood pressure, helping them adhere to antihypertensive lifestyle modifications and drug treatments. ${ }^{5}$

Our current study must be interpreted within the context of several potential limitations. First, because the patients in HOMED-BP received HBP-guided therapy, ${ }^{14}$ their treatment was adjusted according to the selfmeasured HBP, and the office blood pressure was used as complimentary information. Second, we excluded $1095(31.1 \%)$ patients of the randomised HOMED-BP study, including 694 due to an insufficient number of home readings. According to online supplemental table 1 , there is likely little concern about the effect of exclusion on the balance between groups; however, this lack of an effect cannot be fully guaranteed, thus we should practice caution when applying the findings regarding 


\section{Pretreatment systolic office blood pressure $(\mathrm{mmHg})$}

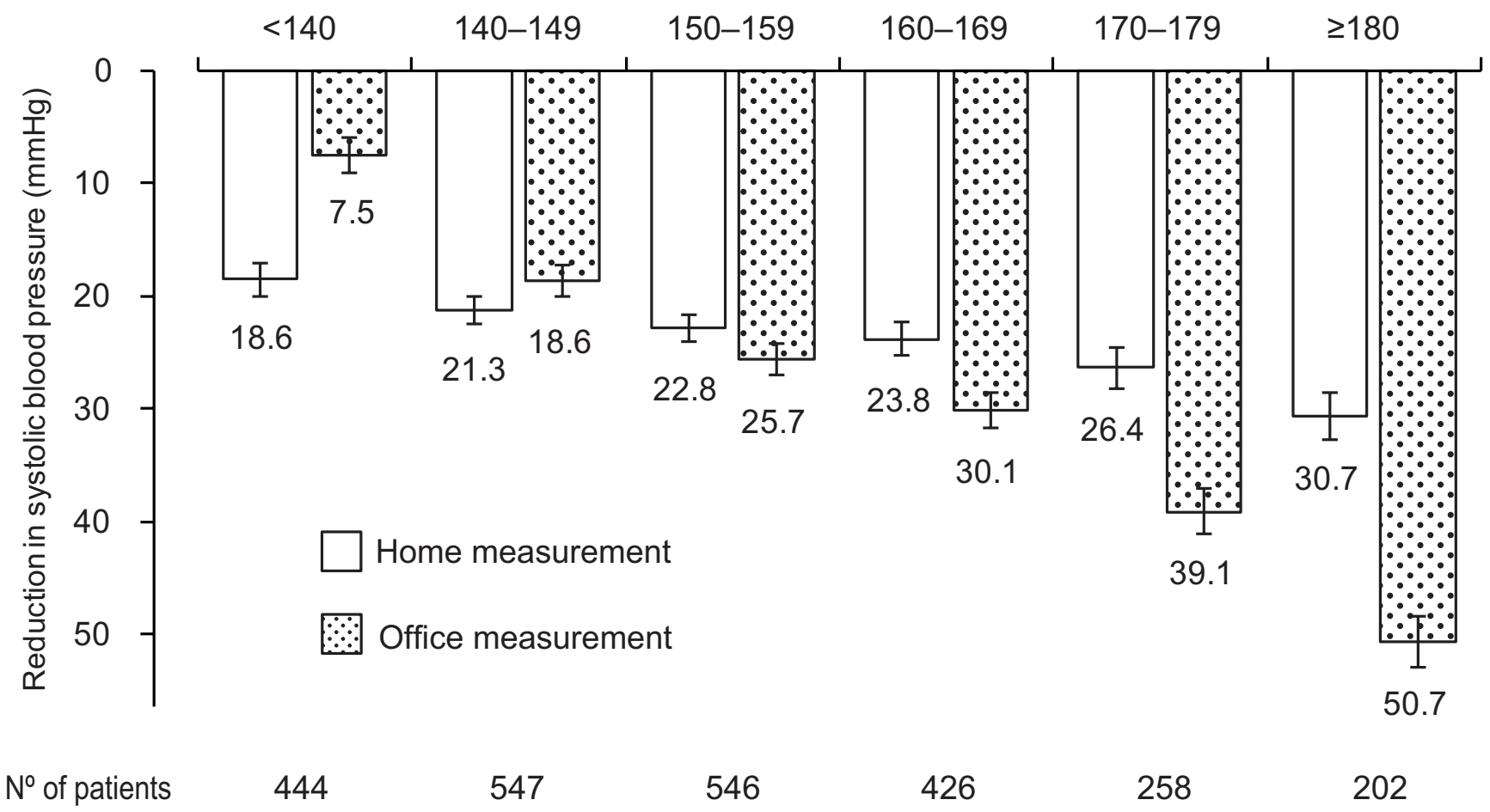

Figure 4 Reduction in the follow-up systolic blood pressure categorised by pretreatment office blood pressure. Error bars indicate $95 \%$ Cls. Data were adjusted for sex, age, body mass index, diabetes mellitus, current smoking and drinking, hypercholesterolaemia, history of cardiovascular disease and DDD at the end of follow-up period (mean: 7.0 years). DDD, defined daily dose.

antihypertensive drug effect to real-world clinical practice. Third, we were unable to assess the placebo effect in the present study because all patients received antihypertensive medication. The placebo effect is a major influencing factor, in addition to Wilder's law and the regression to the mean phenomenon, in the administration of antihypertensive medication. ${ }^{27}$ Fourth, because office blood pressure was measured less than three times at each visit, the regression to the mean on office blood pressure cannot be assessed or compared with that on HBP. Finally, although our results are representative of middle-aged to old-aged Japanese patients, they might not be applicable to other settings or ethnic groups with different distributions of risk factors.

In conclusion, the reduction in the HBP by antihypertensive drug monotherapy was proportional to the HBP during the pretreatment drug-free period, in accordance with Wilder's law. ${ }^{12}$ However, the HBP reduction peaked in the patients who had a high pretreatment HBP $(\geq 155$ $\mathrm{mm} \mathrm{Hg}$ ) when treatment was initiated with low-dose antihypertensive drugs. Patients with a systolic HBP of $\geq 155$ $\mathrm{mm} \mathrm{Hg}$ before treatment might be considered to have resistant hypertension because the effect of low-dose antihypertensive drug for the blood pressure reduction reached the plateau, which seems against Wilder's law; however, we cannot say too much about the issue because we enroled patients with mild-to-moderate essential hypertension in the HOMED-BP study, and those with severe hypertension that tended to be resistant were not enroled. Whether or not Wilder's law can be similarly applied to high-risk patients with severe hypertension remains unclear. However, HBP measurement was minimally affected by regression to the mean, suggesting the usefulness of HBP measurement for estimating the efficacy of antihypertensive drugs. Patients with a high HBP during pretreatment should receive a sufficient amount of antihypertensive medication starting from the very first treatment.

Acknowledgements We would like to express our deepest appreciation to all of the HOMED-BP study collaborators for their valuable contribution. We thank the staff of Teikyo University for their valuable help.

Contributors KA, Yl and TO conceived and designed the study; $\mathrm{AH}, \mathrm{KA}, \mathrm{MK}$ and $\mathrm{YI}$ acquired the data; and KA and HS carried out the statistical analyses. HS drafted the original manuscript with $\mathrm{KA}$ and $\mathrm{AH}$. SM, $\mathrm{YI}$ and TO provided the intellectual input, and all authors critically revised the manuscript and approved the final manuscript. KA is the guarantor.

Funding This study was funded by grants from the Japan Cardiovascular Research Foundation, the Japan Arteriosclerosis Prevention Fund and Tohoku University. Fujitsu Systems East Limited (Tokyo, Japan) and Omron Healthcare Co, Ltd. (Kyoto, Japan) developed and maintained the internet-based infrastructure for the measurement of the blood pressure at home and the management of patients. This study was also supported by Grants-in-Aid for Scientific Research (23390171, $25253059,26860093,16 \mathrm{~K} 15359,17 \mathrm{H} 04126$ and 18K06759) from the Ministry of Education, Culture, Sports, Science and Technology, Japan, and Grants-in-Aid for the Japanese Society for the Promotion of Science (JSPS) fellows (25.7756 and 
25.9328). No funding agencies had any role in the design or conduct of the study; in the collection, analysis or interpretation of the data; or in the preparation, review or approval of the manuscript.

Competing interests $\mathrm{KA}, \mathrm{YI}$ and $\mathrm{TO}$ received research grants from 0mron Healthcare.

Patient consent for publication Not required.

Provenance and peer review Not commissioned; externally peer reviewed.

Data availability statement No data are available.

Supplemental material This content has been supplied by the author(s). It has not been vetted by BMJ Publishing Group Limited (BMJ) and may not have been peer-reviewed. Any opinions or recommendations discussed are solely those of the author(s) and are not endorsed by BMJ. BMJ disclaims all liability and responsibility arising from any reliance placed on the content. Where the content includes any translated material, BMJ does not warrant the accuracy and reliability of the translations (including but not limited to local regulations, clinical guidelines, terminology, drug names and drug dosages), and is not responsible for any error and/or omissions arising from translation and adaptation or otherwise.

Open access This is an open access article distributed in accordance with the Creative Commons Attribution Non Commercial (CC BY-NC 4.0) license, which permits others to distribute, remix, adapt, build upon this work non-commercially, and license their derivative works on different terms, provided the original work is properly cited, appropriate credit is given, any changes made indicated, and the use is non-commercial. See: http://creativecommons.org/licenses/by-nc/4.0/.

\section{ORCID iD}

Kei Asayama http://orcid.org/0000-0003-3365-0547

\section{REFERENCES}

1 Williams B, Mancia G, Spiering W, et al. 2018 ESC/ESH guidelines for the management of arterial hypertension. Eur Heart $J$ 2018;39:3021-104.

2 Umemura S, Arima H, Arima S, et al. The Japanese Society of hypertension guidelines for the management of hypertension (JSH 2019). Hypertens Res 2019;42:1235-481.

3 Law MR, Morris JK, Wald NJ. Use of blood pressure lowering drugs in the prevention of cardiovascular disease: meta-analysis of 147 randomised trials in the context of expectations from prospective epidemiological studies. BMJ 2009;338:b1665

4 Asayama K, Li Y, Franklin SS, et al. Cardiovascular risk associated with white-coat hypertension: Con side of the argument. Hypertension 2017;70:676-82.

5 Imai Y, Hosaka M, Elnagar N, et al. Clinical significance of home blood pressure measurements for the prevention and management of high blood pressure. Clin Exp Pharmacol Physiol 2014;41:37-45.

6 Imai Y, Ohkubo T, Hozawa A, et al. Usefulness of home blood pressure measurements in assessing the effect of treatment in a single-blind placebo-controlled open trial. J Hypertens 2001;19:179-85.

7 Ohkubo T, Imai Y, Tsuji I, et al. Home blood pressure measurement has a stronger predictive power for mortality than does screening blood pressure measurement: a population-based observation in Ohasama, Japan. J Hypertens 1998;16:971-5.

8 Asayama K, Ohkubo T, Kikuya M, et al. Prediction of stroke by self-measurement of blood pressure at home versus casual screening blood pressure measurement in relation to the joint National Committee 7 classification: the Ohasama study. Stroke 2004;35:2356-61.

9 Whelton PK, Carey RM, Aronow WS, et al. 2017 ACC/AHA/AAPA ABC/ACPM/AGS/APhA/ASH/ASPC/NMA/PCNA guideline for the prevention, detection, evaluation, and management of high blood pressure in adults: a report of the American College of Cardiology/ American heart association Task force on clinical practice guidelines. Hypertension 2018;71:e13-115.

10 Schmieder RE, Schmidt ST, Riemer T, et al. Disproportional decrease in office blood pressure compared with 24-hour ambulatory blood pressure with antihypertensive treatment: dependency on pretreatment blood pressure levels. Hypertension 2014;64:1067-72.

11 Soranna D, Zambon A, Corrao G, et al. Different effects of antihypertensive treatment on office and ambulatory blood pressure: a meta-analysis. J Hypertens 2019;37:467-75.
12 Wilder J. Basimetric approach (law of initial value) to biological rhythms. Ann N Y Acad Sci 1962;98:1211-20.

13 Fujiwara T, Nishimura T, Ohkuko T, et al. Rationale and design of HOMED-BP study: hypertension objective treatment based on measurement by electrical devices of blood pressure study. Blood Press Monit 2002;7:77-82

14 Asayama K, Ohkubo T, Metoki $\mathrm{H}$, et al. Cardiovascular outcomes in the first trial of antihypertensive therapy guided by self-measured home blood pressure. Hypertens Res 2012;35:1102-10.

15 Watabe D, Asayama K, Hanazawa T, et al. Predictive power of home blood pressure indices at baseline and during followup in hypertensive patients: HOMED-BP study. Hypertens Res 2018;41:622-8.

16 Hansson L, Hedner T, Dahlöf B. Prospective randomized open blinded end-point (PROBE) study. A novel design for intervention trials. Blood Press 1992;1:113-9.

17 World Medical Association. World Medical association Declaration of Helsinki: ethical principles for medical research involving human subjects. JAMA 2013;310:2191-4.

18 Chonan K, Kikuya M, Araki T, et al. Device for the self-measurement of blood pressure that can monitor blood pressure during sleep. Blood Press Monit 2001;6:203-5.

19 White WB, Anwar YA. Evaluation of the overall efficacy of the Omron office digital blood pressure HEM-907 monitor in adults. Blood Press Monit 2001;6:107-10.

20 Asayama K, Ohkubo T, Hanazawa T, et al. Does antihypertensive drug class affect day-to-day variability of self-measured home blood pressure? the HOMED-BP study. J Am Heart Assoc 2016;5:e002995.

21 Satoh M, Haga T, Hosaka M, et al. The velocity of antihypertensive effects of seven angiotensin II receptor blockers determined by home blood pressure measurements. J Hypertens 2016;34:1218-23.

22 World Health Organization. World Health organization collaborating centre for drug statistics methodology system of defined daily doses, 2018. Available: http://www.whocc.no/atc_ddd_index/ [Accessed 14 Sep 2018].

23 Staessen J, Amery A, Fagard R. Isolated systolic hypertension in the elderly. J Hypertens 1990;8:393-405.

24 Kenward MG, Roger JH. Small sample inference for fixed effects from restricted maximum likelihood. Biometrics 1997:53:983-97.

25 Asayama K, Ohkubo T, Rakugi H, et al. Comparison of blood pressure values-self-measured at home, measured at an unattended office, and measured at a conventional attended office. Hypertens Res 2019;42:1726-37.

26 Ogata S, Kamide K, Asayama K, et al. Genome-Wide association study for white coat effect in Japanese middle-aged to elderly people: the HOMED-BP study. Clin Exp Hypertens 2018;40:363-9.

27 Messerli FH, Rexhaj E. Of headwind and tailwind, regression to the mean and Wilder's principle. J Hypertens 2019;37:4-5.

28 Ohkubo T, Asayama K, Kikuya M, et al. How many times should blood pressure be measured at home for better prediction of stroke risk? Ten-year follow-up results from the Ohasama study. $J$ Hypertens 2004;22:1099-104.

29 Vaur L, Dubroca I, Dutrey-Dupagne C, et al. Superiority of home blood pressure measurements over office measurements for testing antihypertensive drugs. Blood Press Monit 1998;3:107-14.

30 Moore MN, Atkins ER, Salam A, et al. Regression to the mean of repeated ambulatory blood pressure monitoring in five studies. $J$ Hypertens 2019;37:24-9.

31 Asayama K, Hozawa A, Taguri M, et al. Blood pressure, heart rate, and double product in a pooled cohort: the Japan arteriosclerosis longitudinal study. J Hypertens 2017;35:1808-15.

32 Wolf-Maier K, Cooper RS, Banegas JR, et al. Hypertension prevalence and blood pressure levels in 6 European countries, Canada, and the United States. JAMA 2003;289:2363-9.

33 Borden WB, Maddox TM, Tang F, et al. Impact of the 2014 expert panel recommendations for management of high blood pressure on contemporary cardiovascular practice: insights from the NCDR PINNACLE registry. J Am Coll Cardiol 2014;64:2196-203.

34 Xu W, Goldberg SI, Shubina M, et al. Optimal systolic blood pressure target, time to intensification, and time to follow-up in treatment of hypertension: population based retrospective cohort study. BMJ 2015;350:h158.

35 Gradman $\mathrm{AH}$, Parisé $\mathrm{H}$, Lefebvre P, et al. Initial combination therapy reduces the risk of cardiovascular events in hypertensive patients: a matched cohort study. Hypertension 2013;61:309-18.

36 Spence JD, Rayner BL. J curve and cuff artefact, and diagnostic inertia in resistant hypertension. Hypertension 2016;67:32-3.

37 Phillips LS, Branch WT, Cook CB, et al. Clinical inertia. Ann Intern Med 2001;135:825-34. 